\title{
TOWARDS A KNOWLEDGE COMMUNICATION PERSPECTIVE ON DESIGNING ARTEFACTS SUPPORTING KNOWLEDGE WORK
}

\author{
Niclas Eberhagen \\ Linnaeus University, Sweden, niclas.eberhagen@lnu.se \\ doi:10.13165/ST-14-4-2-02
}

\section{Abstract}

The designing of computer-based artefacts to support knowledge work is far from a straightforward rational process. Characteristics of knowledge work have a bearing upon how developers (or designers), together with users, come to approach and capture the rich and tacit knowing of the practice. As all knowledge work is about the production of knowledge, transforming it, so is the design practice for developing artefacts to occupy space within that same practice. There is a need for providing a conceptual language to better reflect the nature of this design work that goes beyond those dressed in the managerial (or rational) language of planned activities and deliverables. Towards this end, a conceptual frame is presented that makes several important aspects of the design practice visible. The frame brings together both nature of design work and characteristics of knowledge work to extend the frame of knowledge in user-developer communication of Kensing and Munk-Madsen. Thereby, providing a means to focus attention and dress debate on what situated designing is. By using explicit concepts, such as types knowledge domains embedded in the design situation, the transitional paths between them, and design engagements, it arms practitioners with specific linguistic constructs to direct attention and efforts in planning and organizing development undertakings.

Purpose - the purpose of this work is to present and argue for a perspective on designing of computer-based artefacts supporting knowledge work. This is done to inform practitioners, directing their attention and dressing debate, and providing a conceptual language to better capture design activities in planning and organizing development undertakings. 
Design/Methodology/Approach - The approach presented in this article is conceptual in so far that a model or frame providing linguistic constructs is constructed and argued, building upon scholarly work of knowledge communication and drawing upon previous findings from empirical encounters.

Findings - A conceptual frame is presented that captures the design situation as a situated knowledge communication process.

Research limitations/implications - The conceptual frame presented remains yet to be validated in practical application. This may be achieved either using it as a lens to uncover and explain phenomena in similar design work, thereby putting its explanatory power to the test, or using it to direct future development undertakings, thereby putting its predictive power to the test.

Practical implications - The practical implications of the design frame lies in its power to provide linguistic constructs to direct one's effort in planning and organizing development undertakings, and in extension to provide argument for decision-makers allocating resources.

Originality/Value - By extending the model of knowledge communication of Kensing and Munk-Madsen, and framing it within a situated design context, it better reflects characteristics of knowledge work, providing practitioners with the means to better organize design activities.

Keywords - situated designing, knowledge work context, conceptual model, knowledge communication, computer-based artifacts.

Research type - conceptual.

\section{Introduction}

Designing of computer-based artefacts to support knowledge work is far from a straightforward rational process. Characteristics of knowledge work have a bearing upon how developers, together with users, come to approach and capture the rich and tacit knowing of the practice. Drawing upon scholarly work on knowledge work (Scarbrough, 1999a; Scarbrough, 1999b; Schultze, 2000), knowledge in practice (Orlikowski, 2002; Nonaka, 1994; Nonaka and Takeuchi, 1995; Brown and Duguid, 1998; Wenger, 1998; Newell et al., 2002), and on learning in practice (Torraco, 1999; Tyre and Von Hippel, 1997; Argyris and Schön, 1978; Lave, 1991; Lave and Wenger, 1991; Brown and Duguid, 1991; Orr, 1996) knowledge work may be characterized as follows.

First, the knowledge work practice is about work that is emergent and non-routine, in some instance highly creative. It may be seen as a response to arising situational conditions and not easily captured in work scripts, and as making do with what is at hand, e.g., "bricolage" (Weick, 1993). This work not only transforms and produces knowledge, but also draws upon sources of tacit knowledge for its completion. It is work that is situated, in so far that it is the living context of the work that makes it meaningful, not only to the one participating and engaged in it, but also to those contributing to and benefiting from it. It is thus social in that meaning, i.e., how observed phenomena should 
be interpreted and understood is socially constructed and negotiated. For the output of the work to be useful and meaningful to others, it must be recognized as such beyond the immediate borders of the practice.

Second, knowledge in the practice is always tacit, a human property which meaning is socially defined and negotiated, as pointed out above. Such tacit knowledge cannot simply be separated from the practice, captured, packaged and exported as a de-contextualized commodity and applied in another setting effectively. It is only made visible through the ongoing enactment in and the activities within the practice. The dependency upon or inseparability from a living ongoing practice favors a view of knowledge best described as knowing enacted in practice. Such a view summarizes the points made above and at the same time highlights not only the situated nature of knowing practice, but also both its tacit and social dimensions. The way to become knowledgeable in and of the practice is to be engaged in its activities.

Third, knowing in practice and learning in practice are two sides of the same coin. They are inseparable or at least tightly coupled to each other, the one conditioning the other. Learning is thus situated in practice and inseparable from the engagement in practice, requiring an active work setting. New understandings and retransformations of older ones cannot be arrived at unless framed within a living context for trying out insights and gaining experience. Work-based learning cannot simply be achieved in a classroom setting, as it is for newcomers a process of being enculturated into the practice, observing and gradually trying it out for oneself, and for old-timers a process of honing their skills and being confronted with phenomena at the border of their understanding and competence.

The design practice, in the context of knowledge work, should not be viewed as a formal planned effort, as a more traditional engineering approach, which objectifies knowledge of the design situation by assuming that goals may be expressed clearly and understood at the outset of the effort (Eberhagen, 2011). As all knowledge work is about the production of knowledge, transforming it, so is the design practice for developing artefacts to occupy space within that same practice.

Thus, a need emerges for providing a conceptual language to better capture the image of development work that goes beyond those dressed in managerial languages as a planned activity, to direct one's focus to talk about specific types of knowledge domains embedded in the design situation and the transitional paths between them.

Towards this end, a conceptual frame is presented that makes several important aspects of the design practice visible. It shows that the design process is highly situated, that it cannot take place outside the work context, but in close interdependent relationship. It provides a means to focus attention and dress debate on what situated designing is. By using explicit concepts, such as types of processes of knowledge transitions and design engagements, an operationalization of the conceptual frame (or model) is enabled for studying and exploring situations of situated designing. By extending the model of knowledge, communication of Kensing and Munk-Madsen, and framing it within a situated design context, it better reflects characteristics of knowledge work, providing practitioners with the means to better organize design activities. The practical implications of the design frame lie in its power to provide linguistic constructs to direct one's effort in 
planning and organizing development undertakings, and in extension provide argument for decision-makers allocating resources.

The design perspective lends inspiration from the work of Suchman (2007) on the situatedness of learning and design and Schön $(1983$; 1992) on the nature of design practice, and is based on the seminal work of Kensing and Munk-Madsen (1993) on knowledge communications in designing.

The article is structured as follows. First, a theoretical background of the work of Kensing and Munk-Madsen is given. Then, the theoretical frame is presented, wherein an outline of the situated design perspective, derived from previous work, is presented. Lastly follows an elaboration of the conceptual frame, including knowledge domains and communications processes, knowledge transitions processes and design engagements.

\section{Theoretical background}

Knowledge of the design situation is an elusive concept, yet one may instantly recognize that design is about transformation of knowledge, i.e. transforming the current understanding of the wants and needs of the situation at hand (work practice) and the possibilities of technology (materials) into a manifestation of an artefact (a system). However, this emphasizes the question of what this knowledge is, and how to talk and think about it if one cannot name it and frame it. It is obvious that there is a need for a vocabulary with which to dress the phenomena. For this reason, one may turn to the seminal work of Kensing and Munk-Madsen (1993) that has contributed much in this direction. In coming from the participatory design tradition, they explore areas or categories of knowledge communication between users and developers in the design situation.

Kensing and Munk-Madsen see design as a bridge-building activity or process that creates something new, the system, out of two separate domains: the user's present work and the technological options available. Here, users are seen as having knowledge of their present work and of organizational options, and developers are seen as having knowledge of the technical options available. These knowledge domains are what to expect that the users and developers have at the starting point of the development process, which is all they really need, and these must be developed and integrated for the design process to be successful.

The framework of Kensing and Munk-Madsen deals with three domains of knowledge: the user's present work; the technological options available, not only the technology as such, but also the work organization; and the new system and changes in the content and the organization of the user's work. Their framework deals with these domains both from an abstract and concrete level. Kensing and Munk-Madsen point out that abstract knowledge is needed to gain an overview of a knowledge domain and concrete experience is needed to understand the abstract knowledge. Thereby, six knowledge areas are yielded, as shown in Table 1. 
Table 1. Knowledge domains in user-developer communication (adapted from Kensing and Munk-Madsen, 1993, p. 80)

\begin{tabular}{|l|l|l|l|}
\hline & \multicolumn{1}{|c|}{ Users' present work } & \multicolumn{1}{|c|}{ New system } & Technological options \\
\hline Abstract knowledge & $\begin{array}{l}\text { Relevant structures } \\
\text { on users' present work } \\
(2)\end{array}$ & $\begin{array}{l}\text { Visions and design } \\
\text { proposals (5) }\end{array}$ & $\begin{array}{l}\text { Overview of } \\
\text { technological options } \\
(4)\end{array}$ \\
\hline Concrete experience & $\begin{array}{l}\text { Concrete experience } \\
\text { with users' present } \\
\text { work (1) }\end{array}$ & $\begin{array}{l}\text { Concrete experience } \\
\text { with the new system } \\
(6)\end{array}$ & $\begin{array}{l}\text { Concrete experience } \\
\text { with technological } \\
\text { options (3) }\end{array}$ \\
\hline
\end{tabular}

According to Kensing and Munk-Madsen, the six knowledge domains of Table 1 are defined as follows:

- Concrete experience with users' present work is necessary for the developers to understand and produce structured descriptions of representations of this work and to judge their relevance. Developers cannot rely solely on the users talking about their work or requirements specification, but must experience them in action.

- Relevant structures on users' present work provide a common and rigorous language in which users and developers can communicate, showing the present situation in the user organization, and used to identify desired changes and evaluate consequences of proposed designs.

- Concrete experience with technological options enables users to play an active role in the development process by stimulating their imagination and giving them a better understanding of abstract descriptions of technical and organizational solutions. It is equally important to developers to gain experience with organizational options if they are to play an active role in designing the use of technology in the organization and understand the users.

- Overview of technological options provides input of technical and organizational ideas into the design process for the developers in order to ensure that the new computer system and the new organization fit together.

- Visions and design proposals are descriptions that are developed through the lifetime of the project, documenting the progress and forming the basis for renewed contracts, and as such they must be understandable to the users. In order for them to make decisions and assign priorities, they need abstract descriptions of the new computer system and the organization in which it is going to be implemented.

- Concrete experience with the new system enables users to understand abstract descriptions of the new system and experience how it comes to meet their needs. Such experience is also important to the developer in order to check whether the new system meets the descriptions.

Kensing and Munk-Madsen define areas of knowledge that must be acquired by either the users or the developer during the development process, and point out the responsibilities and role of the developer with regard to this. Here, they first point out that it is the responsibility of the developers to help the users in developing relevant structures 
on users' present work, visions and design proposals, and concrete experience with the new system. Abstract descriptions are needed for the users in order to evaluate design proposals and make decisions about accepting or rejecting them, and for them to take an active role in the design process. However, users need concrete experience with the new system before they can understand abstract descriptions of it. They also point out that it is the responsibility of the developers to develop visions and design proposals, relevant structures on users' present work and gain concrete experience with users' present work and concrete with the new system. Developers must understand abstract descriptions of the new system, since they are major intermediate results, and relevant structures on users' present work in order to identify and evaluate desirable changes. Having concrete experience with users' present work, in order to understand and produce descriptions of relevant structures on the users' present work, enables them to better communicate with the users and understand events in the users' organization. Having concrete experience with the new system is necessary in order for them to be able to test and evaluate it.

Although the work of Kensing and Munk-Madsen may seem to be prescriptive, i.e. pointing out different techniques and tools to be used in different situations of knowledge communication in the design situation, it may also provide a means to help focus upon areas of knowledge communication or integration activities in the design process. It may help to understand not only what areas are important to pay attention to, but also when. In the work of Pries-Heje and Dittrich (2009), this has been precisely the case. They have used the framework of Kensing and Munk-Madsen as an analytical instrument to look upon how different knowledge integration activities were supported in an ERP implementation and adaption as an explanation to what went wrong or was problematic in the process. Although it may not be apparent that an ERP implementation may be regarded as design, they argue that one must understand it in terms of a socio-technical design process, requiring knowledge integration across several domains, to recognize that appropriate knowledge integration activities are necessary to undertake, with strong user participation, for it to be successful. The work of Pries-Heje and Dittrich shows promises, not because ERP implementation processes are any concern here, rather, it shows the potential of the framework of Kensing and Munk-Madsen as an analytical instrument, a means to focus upon areas of knowledge communication activities, and as a vocabulary to talk about and understand these in the design situation.

The model of knowledge domains in user-developer communication of Kensing and Munk-Madsen is also used as an integral part of the MUST method's repertoire of tools and techniques for identifying needed knowledge sources (areas) in an IT-design project (Bødker et al., 2004). Here, it is used in connection with different performance-oriented data gathering techniques to identify areas where knowledge needs to be generated, such as both abstract knowledge and concrete insights into the users' experience of present work practices, of technological options or of newly proposed systems.

In the work of Kensing and Munk-Madsen, one may find not only a much needed instrument to focus on which knowledge communication domains and activities are important to address and when, but also a vocabulary and frame to express oneself within. Here, it is possible to use their framework, inspired by how Pries-Heje and Dittrich have used it in their own work, in several ways. It may be used as a lens to 
understand or highlight which knowledge domains need to be addressed in designing computer-based systems. Then, it may be used as a means to identify or clarify the role and responsibility of who develops the knowledge belonging to these different domains, and when to develop it. Furthermore, it may be used as a means to analyze if, and how, the different knowledge domains are integrated with the design situation or process, and what activities support this.

\section{The theoretical frame}

The theoretical frame or the situated design perspective consists of two parts. First, it has frame for the situated design practice, and second, it has a knowledge communication perspective of designing. The frame has been elaborated in Eberhagen (2011) and partly presented in Eberhagen (2014), and will only be briefly summarized here before moving on to the knowledge communication perspective.

\section{The situated design practice}

The situated design perspective lends its inspiration from authors, such as Suchman (2007) and Schön $(1983 ; 1992)$. The design practice is depicted as consisting of three overlapping worlds of design activities, see Fig. 1.

In the shared envisioned world, it is the "arena" where user and developers come together to make sense and reach a common understanding of where and how they are heading. It is a world of conceptualization, socialization, an arena for enculturation into each other's worlds. Users need to be invited into the world of technological possibilities and constraints, to see what can be done and get an understanding of how it may be realized. Developers need to be invited into the world of the practitioners to build a frame of understanding on which they can lean upon in realizing the design. Into the private interpreted world, the developers interpretation of what the future system will look like, how it will merge with and function within the work practice are brought. Assumptions about the artefact and practice are tested against the vision and may give rise to a need for reinterpretation and brought back to the shared envisioned world to further the fuel the debate there. The private experienced world is where the users work (enact), i.e. experiencing the everyday ongoing business. It is a world that is more or less private to them from the perspectives of the developers, where part of their domain may be gleaned through the feedback when they play with the designs, or in the shared envisioned through building a common vision.

From the shared envisioned world, the developers or designers bring with them their vision of what the artefact is about, the understanding of what the practice is and what the users want. This interpreted vision is what guides and drives the design. As the design enfolds and comes to embody the designers understanding, it may give rise to tension between the vision and the artefact. A need for reinterpretation of the vision arises, framed as either questions for clarification or suggestions for further design. 
In between the private experienced world of the users and the private interpreted world of the developers or designers, the vision either belongs in a state of materialization or as experienced. At some point during the designing, the artefact reaches a stage when enough of the interpreted vision of the designers has congealed into physical form and a need for putting it to test arises. The artefact is only experienced by the users once it is introduced into the practice, i.e. delivered in a materialized form.

Finally, in between the shared envisioned world and the private experienced world the vision of the artefact belongs in either a state of being envisioned or reflected. From the shared envisioned world, the users will naturally carry with them their idea of what the system will be like, their expectations. As the materialized vision is delivered into their domain and confronted with their everyday on-goings, becoming experienced, it is only natural to expect some form of reaction. This could seed the reflection, learning, and questioning of their vision, and could be brought back to the shared envisioned world at the next meeting there.

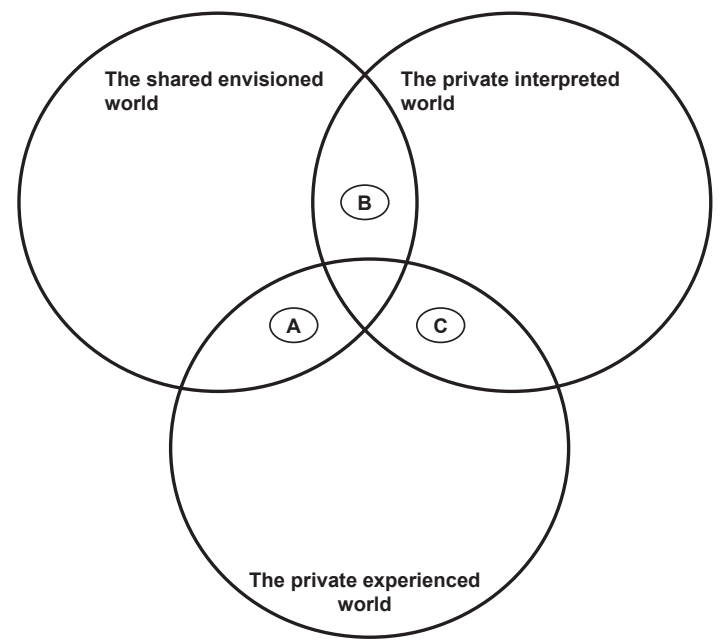

Figure 1. The situated design frame of overlapping design worlds and activities: A) envisioning and reflection, B) interpretation and reinterpretation, and C) materialization and experiencing

Now it is time to complement the above frame for designing with a knowledge communication perspective on designing. This will be done throughout the ensuing three sections.

\section{Knowledge domains and communication processes}

If designing is all about transforming the knowing gained in the situation, which is the position taken in this work, and its communication between different sub-worlds (see Fig. 1), then questions may arise cornering the nature of that knowing, i.e. the knowledge in designing. It is here that the work of Kensing and Munk-Madsen (1993) may contribute with a focus on knowledge domains and communication processes (an account of their work may be found in a previous section). 
From the work of Kensing and Munk-Madsen, the flows of knowledge communication between different domains in the design situation may be summarized as shown in Fig. 2, something which also Pries-Heje and Dittrich (2009, p. 49-51) seem to agree with.

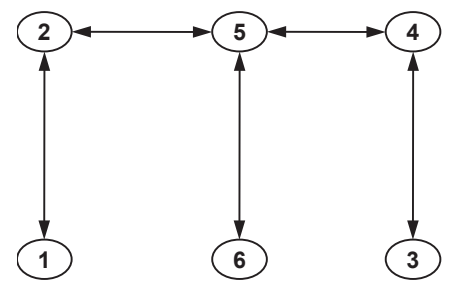

Figure 2. Knowledge communication (see Table 1 for numbers)

However, this view seems to be a bit simplified, depicting knowledge transitions as being restricted to certain paths. The reaching of a specific state or domain of knowing may only be achieved through a chain of dependencies, or pre-determined or preconditional transitions. It seems to obscure the possibility of more direct influences. Here is proposed a more dynamic approach that view knowledge communication as more process-oriented (see Fig. 3), where the different dependencies are more direct, creating other possible transitional paths.

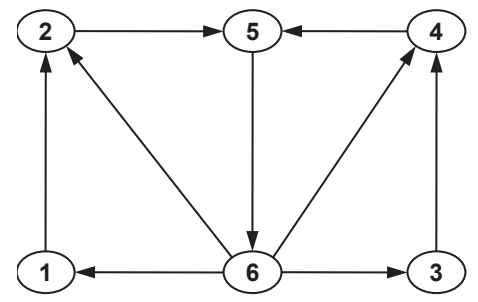

Figure 3. Process view (see Table 1 for numbers)

Thus, one may come to recognize more clearly the situatedness of the design where concrete experience of the system may very well strengthen or enhance the experience (both of the users' and of the designers') of the work context and technological options. This view emphasizes the central role of the evolving system, the ever more materialized understanding, and it plays as an engine in driving the design process. It gives a more adequate image of the development process of a prototype system as an instrument of learning, as a means to make sense of where one is and may be heading. It emphasizes that the whole design takes place somewhere, i.e., it is situated or located (Suchman, 2002).

As most knowledge "communication" is taking place in the overlapping of the subworlds, it seems only natural to place the "origins" of these knowledge domains at the intersections of the different sub-worlds (see Fig. 4). 


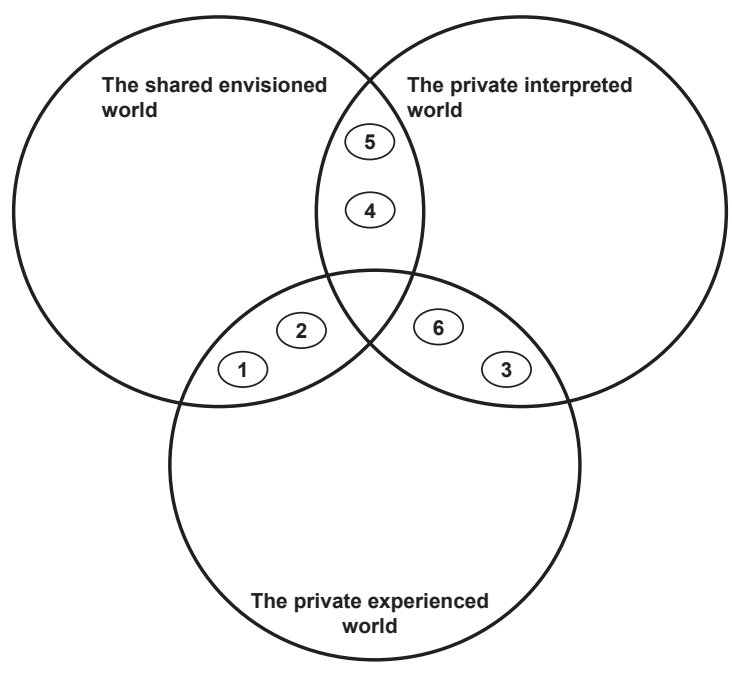

Figure 4. Design worlds with knowledge domains (see Table 1 for numbers)

Here, the origins of knowledge domain 1 and 2 are placed in the overlap zone between the private experienced world and the share envisioned world. The transitions between them reflect the way experience of the work practice lends itself to the building of abstract knowledge of the same, and that the abstract knowledge in turn becomes the means to question the work practice. Concrete experience of the work practice is foremost brought into the design situation through the users and to some extent by the developers, or designers, depending upon their engagement in the same.

Further, the origins of knowledge domain 4 and 5 are placed in the overlap zone between the shared envisioned world and the private interpreted world. Visions and design proposals of the future system are constructed in a confrontation with an overview of technological options in a "mutual dance" of interpretation and reinterpretation. It is a mutual process of transition since the establishment of the vision of the future system may question, strengthen and expand the understanding of what is possible with technology, and the current understanding of what is possible to achieve may shape the vision of the future system. Knowledge of the new system at this abstract level is of course generated in a mutual process between the users and designers, each bringing with them their set of expectations, experience and understandings.

Finally, the origins of knowledge domains 3 and 6 are placed in the overlap zone between the private experienced world and the private interpreted world. Both concrete experience with technological options, such as similar systems and tools, as well as concrete experience with the new systems are gained and communicated here. Designers gain experience with the new system as they develop it, test it, and gather feedback from the users. Likewise, users gain their experience when the materialized system, representing the current understanding of the future system, is brought into their work context. 
The placing of the origins of the knowledge domains seems very convenient. However, parts or aspects of the knowledge domain 2 may very well be found to "spill over" into the overlap where both domains 4 and 5 are placed. One has just to return to Fig. 3 to remind oneself that due to the nature of the transitional dependencies, this must be the case. Looking at the other overlaps, the same relations may be found there, as well. The correct way to talk about the placement of the knowledge domains would be to say that they seem to be predominantly originating or belonging to one overlap zone or another.

\section{Knowledge transition processes}

Now it is time to examine what kind of processes may be derived from Fig. 3 and Fig. 4. The three overlapping zones yields three knowledge transitions processes. They are labeled as follows: practice driven, technology driven, and conceptualization driven. Other types of processes could be derived from Fig. 3, as other types of transitional paths are possible. The numbers in Figs. 5-7 correspond to the knowledge domains of Table 1.

The first knowledge transition process is one that is predominantly driven by the practice, involving a transition of the knowledge domains depicted in Fig. 5.
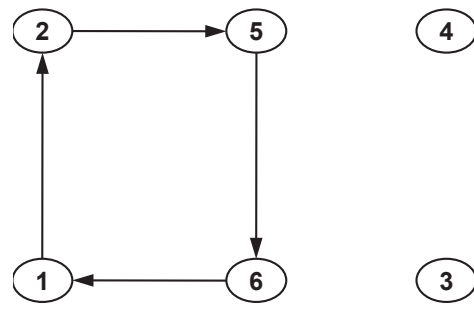

Figure 5. Practice driven - knowledge transition \#1

(see Table 1 for numbers)

In the first knowledge transition process, experience with the work practice helps building a representation of it, which in turn feeds the formation of a vision of the future system. This vision of the future system has direct bearing upon the materialization of the prototype system, leading to the enablement of the users to experience it in the work context and so forth. The prototype system comes to function as an instrument for better understanding and representation of the practice. Two entry points might be appropriate here. Practical experience with the work practice could give rise to a need to improve upon in it, leading to abstract representations and analysis of it. One could also start to model without any prior practical experience, without being burdened with what is possible or not in the current practice, and thus, envision a bright new world or future without any constricting historical luggage.

The second knowledge transition, shown in Fig. 6, depicts a process that is driven predominantly by what is possible to achieve with or through technology (or understanding of the technology). 


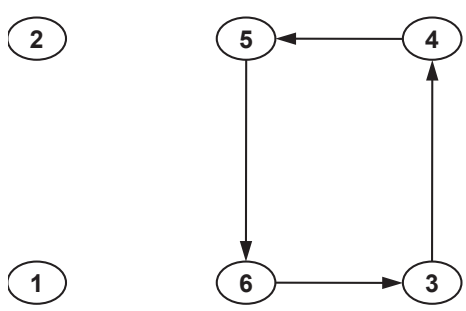

Figure 6. Technology driven - knowledge transition \#2

(see Table 1 for numbers)

In the second knowledge transition process, previous experience of similar technological (or design) solutions could lead to an improvement of the understanding of what is possible to achieve, what the technology may or may not offer. Such an understanding may very well influence how the vision of a future system would look like. The practical experience of the materialized system then becomes an addition to the base of concrete experience of similar systems or technological solutions, merging with and expanding it. There are several possible starting points for this process. A predominantly technology driven process could start with either knowledge domain 3, 4 or 5, all depending upon what kind of previous experience one has. Concrete experience with similar systems could spur a mission of improvement, a search for better solutions. The understanding of the technological options, of what may be achieved in a future better world, could spur a round of envisioning what such a new system would look like. It is a bit more difficult to see how the process could originate from knowledge domain 5, unless one admits that a technological driven process is dependent upon to some degree, in parallel or sequentially, by a more practice driven process.

The third knowledge transition process is one that is predominantly conceptual driven, as shown in Fig. 7. It is a process, which is heavily dependent on the abstract understanding of what could or should transpire in both the work practice and what options technology may offer.

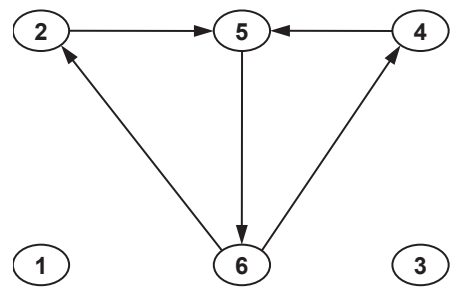

Figure 7. Conceptualization driven - knowledge transition \#3 (see Table 1 for numbers)

The third knowledge transition process seems to be driven, concurrently, from both the knowledge domains 2 and 4 . Both are necessary in the formation of a design proposal or vision of the future system, although it may be an ideal image as there are no apparent dependencies paths from any concrete experience of either the work practice itself or what similar systems could offer. Concrete experience with the new system may 
strengthen both of the domains of abstract knowledge as it now comes to represent the materialized understanding of the ideal world. Thus, a round of reflections may well be triggered concerning whether the abstract understanding is sufficient or adequate to represent properly the "ideal system", e.g., the designing database schemas.

These transitional processes are then placed at their respective overlapping zone in the model of Fig 1. The activities of envisioning and reflection in zone A) seem to be predominately a practical driven transition process. The activities of interpretation and reinterpretation zone B) seem to be predominantly a conceptual driven knowledge transition process. Finally, the activities of materialization and experiencing of zone C) seem to be predominately a technology driven knowledge transition process.

\section{Design engagements}

Here, how the different knowledge transition processes relate to the design activities of the situated design frame, previously briefly introduced, is examined. They are shown in Figs. 8-10. These figures may seem very unambiguous and stylized, but they represent the most predominant paths. The numbers in Figs. 8-10 correspond to the knowledge domains of Table 1.
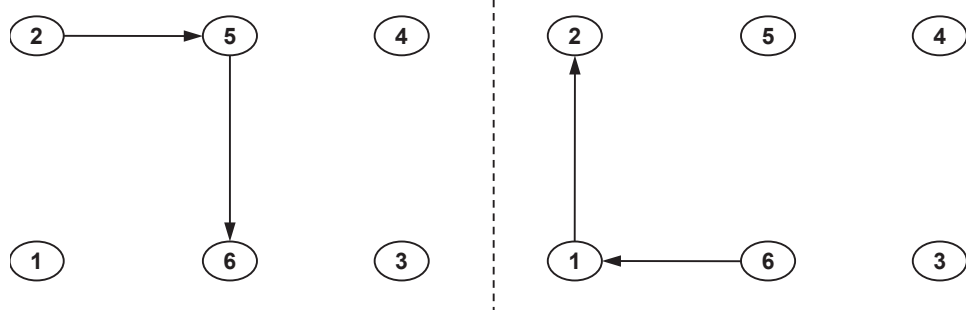

Figure 8. Practice driven design engagements: Envisioning - Reflection (see Table 1 for numbers)

In Fig. 8, the design engagement "envisioning" is shown as the design solution, emerging guided by the abstract understanding of work practice and involving a knowledge transition process. The design engagement "reflection" is shown as the proposed design serving as a means of questioning or exploring the work practice.
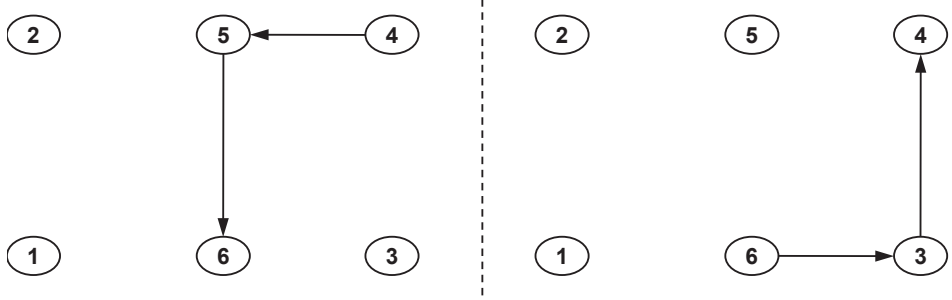

Figure 9. Technology driven design engagements: Materialization - Experiencing (see Table 1 for numbers) 
In Fig. 9, the design engagement "materialization" is shown as the design solution being predominantly guided by the understanding of possible or available technological options. The design engagement "experiencing" is shown as concrete experience of design that questions or informs the understanding of possible design solutions. It is possible to see this as concrete experience with the proposed system solution informing the abstract understanding of the same (the vision), through the broadened understanding of, concrete or abstract, technological options available.
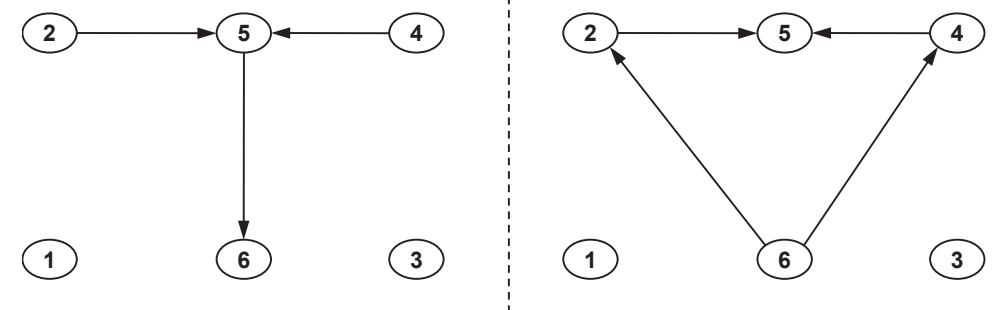

Figure 10. Conceptualization driven design engagements: Interpretation - Reinterpretation (see Table 1 for numbers)

In Fig. 10, the design engagement "interpretation" shows design as guided by the abstract understanding of the work practice and the possible or available technological options. The design engagement "reinterpretation" shows design solution as questioning or informing the abstract understanding of the work practice and possible technological options.

Of course, one could argue that any move from 5 to 6, taken in isolation, would mean some form of materialization. However, then one might forget from where the seed to this step comes, that the embodiment of any understanding is dependent on how it could or should be realized through technology, to which the abstract understanding of technological options strongly contributes. Then it could be argued that it is not enough, the materialization clearly must be dependent upon the abstract understanding of the work practice, as well. Similar arguments could be used for all of the individual transitional steps. However, none of these types of design engagements happen in isolation, none are truly independent of each other. They happen more or less in parallel, sequentially or in any such combination, feeding of and bleeding into each other. Any move from 5 to 6 is dependent and informed by the other domains of design knowledge. In some instances, one path may be more visible, without the others suffering from it. One may choose to view any specific design situation or incident from any type of engagements to explore issues that are, presently, at the center of one's present interest. However, to gain a rich understanding, all of them should be used, in parallel, sequentially or in any such combinations. The process view shown in Fig. 3 does paint the picture, but it hides and obscures how transitional paths winds through the landscape of designing. In order to explore specific transitional paths and relations and make them sand out from the background, they need to be given names, i.e. placed within a conceptual frame. 


\section{Summing up}

From these three glimpses of the world of designing, it may be apparent that the knowledge transitions described are not isolated, encapsulated and independent of each other. Of course, a conceptual driven design engagement could be influenced, on one hand, by predominantly more practice-driven and, on the other hand, by predominantly more technological driven.

If one was to reflect upon on the other episodes, in similar manner, one would arrive at the same conclusion, as well.

The three different categories of design engagements or knowledge transition processes should not be regarded as steps to be followed in a specific order, prescriptive manner. Instead, they are to be seen and used as cognitive filters to distinguish between different engagements, to focus and guide attention to different issues at a specific time point and situation. All that is needed is to remember that each is part of a history, and possible trajectories into the future, of engagements intricately woven to form a whole design practice.

\section{Conclusions}

What has emerged in this work is a perspective on the designing of artefacts, specifically computer-based, supporting knowledge work, which finds itself moored in the situatedness of design work. Here, the design situation cannot be separated from the work context because of interdependent relationships, as it is designed within the living work context, not designed for an objectified one. As such, it may be poorly captured within the managerial discourse of formal project plans and budget frames, which many development efforts seem to be subjected. Instead, the perspective is clothed in a conceptual frame of explicit linguistic constructs to highlight its constituent worlds, processes and relations. Thereby, providing a means to focus attention and dress debate on what situated designing is, i.e., it provides the very instrument to name and distinguish phenomena. By using explicit concepts, such as types of design engagements and processes of knowledge transitions and sources, an operationalization of the frame is enabled for exploring other situations of situated designing. By extending the model of knowledge communication of Kensing and Munk-Madsen, and framing it within a situated design context, it better reflects characteristics of knowledge work, providing practitioners with the means to better organize design activities.

In essence, design work is knowledge work and needs to be given attention as such. It shares many of the same qualities, e.g., the situatedness, tacitness, the socialness, the unstructured nature of such work and the conditions for how such work is performed. The conceptual frame has come to show design work as knowledge communication processes, transitions and domains (knowledge resources). These may need to be managed or given proper attention to become that vehicle of situated learning that essentially characterizes the crafting of all novel artefacts. Here, the conceptual frame makes it possible to address specific types of knowledge communication processes and 
specific types of knowledge domains (or resources). Thereby, it may provide focus and direction when organizations consider knowledge management issues related to or within development (or design) projects, or in formulating strategies that take into account and promote such work.

The practical implications of the design frame lie in its power to provide linguistic constructs to direct one's effort in planning and organizing development undertakings, and in extension provide argument for decision-makers allocating resources.

The conceptual frame presented remains yet to be validated in practical application. This may be achieved either using it as a lens to uncover and explain phenomena in design work, thereby putting its explanatory power to the test, or using it to direct future development undertakings, thereby putting its predictive power to the test. Towards the first end, this work will continue with an empirical evaluation. Here, a recent industry based development project of maintenance decision support systems (Al-Najjar and Eberhagen, 2010; Eberhagen, 2011) will serve to give flesh to the concepts through richly described episodes of designing, and to show its analytical power.

\section{References}

Al-Najjar, B.; Eberhagen, N. Dynamic and Cost-effective Maintenance Decisions. In Holmberg, K. E-maintenance. London: Springer, 2010, p. 345-390.

Argyris, C.; Schön, D. A. Organizational Learning: A Theory of Action Perspectives. Reading: Addison-Wesley, 1978.

Bødker, K.; Kensing, F.; Simonsen, J. Participatory IT Design: Designing for Business and Workplace Realities. Cambridge, MA: MIT Press, 2004.

Brown, J. S.; Duguid, P. Organizational Learning and Communities of Practice: Towards a Unified View of Working, Learning and Innovation. Organization Science. 1991, 2(1): 40-57.

Brown, J. S.; Duguid, P. Organizing Knowledge. California Management Review. 1998, 40(3): 90-111.

Eberhagen, N. Understanding the Designing of Knowledge Work Support Tools as a Situated Practice. Linnaeus University Dissertations, No 70/2011. Växjö/Kalmar: Linnaeus University Press, 2011.

Eberhagen, N. On the Situated Nature of Designing Knowledge Work Supports
Systems. In Johansson, B.; Andersson, B.; Holmberg N. Perspectives in Business Informatics Research. LNBIP 194. London: Springer, 2014, p. 30-44.

Kensing, F.; Munk-Madsen, A. PD: Structure in the Toolbox. Communications of the ACM. 1993, 36(4): 78-84.

Lave, J. Situating Learning in Communities of Practice. In Resnick, L. B., et al. Perspectives on Socially Shared Cognition. Washington DC: American Psychological Association, 1991.

Lave, J.; Wenger, E. Situated Learning: Legitimate Peripheral Participation. Cambridge: Cambridge University Press, 1991.

Newell, S., et al. Managing Knowledge Work. Basingstoke: Palgrave, 2002.

Nonaka, I. A Dynamic Theory of Organizational Knowledge Creation. Organization Science. 1994, 5(1): 14-37.

Nonaka, I.; Takeuchi, H. The Knowledge Creating Company: How Japanese Companies Create the Dynamics of Innovation. New York: Oxford University Press, 1995. 
Orlikowski, W. J. Knowing in Practice: Enacting a Collective Capability in Distributed Organizing. Organization Science. 2002, 13(3): 249-273.

Orr, J.E. Talking about Machines: An Ethnography of a Modern Job. Ithaca, NY: ILR Press, 1996.

Pries-Heje, L.; Dittrich, Y. ERP Implementation as Design: Looking at Participatory Design for Means to Facilitate Knowledge Integration. Scandinavian Journal of Information Systems. 2009, 21(2): 27-58.

Scarbrough, H. Knowledge as Work: Conflicts in the Management of Knowledge Workers. Technology Analysis \& Strategic Management. 1999a, 11(1): 5-17.

Scarbrough, H. The Management of Knowledge Workers. In Currie, W.; Galliers, R. Rethinking Management Information Systems: An Interdisciplinary Perspective. Oxford: Oxford University Press, 1999b, p. 474-496.

Schön, D. A. The Reflective Practitioner: How Professionals Think in Action. New York: Basic Books, 1983.

Schön, D. A. Designing as Reflective Conversation with the Materials of a Design
Situation. Knowledge-Based Systems. 1992, 5(1): 3-14.

Schultze, U. A Confessional Account of an Ethnography about Knowledge Work. MIS Quarterly. 2000, 24(1): 3-41.

Suchman, L. A. Located Accountabilities in Technology Production. Scandinavian Journal of Information Systems. 2002, 14(2): 91-105.

Suchman, L. A. Human-Machine Reconfigurations: Plans and Situated Actions. 2nd ed. Cambridge: University of Cambridge Press, 2007.

Torraco, R. J. Integrating Learning with Working: A Reconception of the Role of Workplace Learning. Human Resource Development Quarterly. 1999, 10(3).

Tyre, M. J.; Von Hippel, E. The Situated Nature of Adaptive Learning in Organizations. Organization Science. 1997, 8(1): 71-83.

Weick, K. E. Organizational Redesign as Improvisation. In Huber, G. P.; Glick, W. $\mathrm{H}$. Organization Change and Re-design. Oxford, UK: Oxford University Press, 1993.

Wenger, E. Communities of Practice: Learning, Meaning, and Identity. Cambridge: Cambridge University Press, 1998. 